Copyright (C) 2020 University of Bucharest Printed in Romania. All rights reserved

ISSN print: $1224-5984$

ISSN online: $2248-3942$
Rom Biotechnol Lett. 2020; 25(2): 1334-1339

doi: $10.25083 / \mathrm{rbl} / 25.2 / 1334.1339$

Received for publication, February, 20, 2018

Accepted, October, 15, 2019

Original paper

\title{
The assesment of the influence induced by LED-s irradiation on basil sprouts (Ocimum basilicum L.)
}

\author{
ANCA DANIELA RAICIU ${ }^{1}$, OANA LIVADARIU ${ }^{2}$, CRISTIAN-PAUL ȘERBĂNIC $\breve{A}^{2}$ \\ ${ }^{1}$ University of Titu Maiorescu, Faculty of Pharmacy Department of Pharmacognosy, \\ Phytochemistry, Phytoterapy, Gh. Sincai Street no. 16, 4 District, Bucharest, Romania \\ ${ }^{2}$ USAMVB, Faculty of Biotechnologies, 59 Bd. Marasti, 011464 Bucharest, Romania
}

\begin{abstract}
The aim of this paper is to demonstrate the effect of light treatments using LED-s and sunlight as well as the effect of charcoal use as substratum instead of soil or gauze. In this paper it is assessed the length and weight of basil (Ocimum basilicum L.) sprouts, namely fresh weight of sprouts, cotyledons, hypocotyls and roots and length of roots and hypocotyls. The tests were done under LED light, to be specific, white, red, blue and green, and sunlight. The used substratum was gauze and charcoal. The results showed that when charcoal substratum was used, higher weights of fresh sprouts, hypocotyls, cotyledons and lengths of hypocotyls were achieved from the massive carbon rich environment. When gauze was used as substratum, the only higher values were obtained in the root length, which is not an edible part of the sprout and this proves that charcoal substratum has a beneficial effect on basil sprouts.
\end{abstract}

Keywords Basil sprouts, LED-s, substratum.

To cite this article: RAICIU AD, LIVADARIU O, ȘERBĂNICĂ C-P. The assesment of the influence induced by LED-s irradiation on basil sprouts (Ocimum basilicum L.). Rom Biotechnol Lett. 2020; 25(2): 1334-1339. DOI: 10.25083/rb1/25.2/1334.1339

*Corresponding author: ANCA DANIELA RAICIU, Chemist, Analitycal Chemistry, Faculty of Chemistry, PhD in Pharmacy, Lecturer, E-mail: daniela_raiciu@yahoo.com

OANA LIVADARIU, Engineer's degree Biotechnology, Dr., Senior Lecturer, E-mail: ombioteh@gmail.com

CRISTIAN-PAUL ŞERBĂNICĂA, Engineer's degree in Biotechnology, Student at Biotechnology and Entrepreneurship Master, E-mail: serbanicapaul@gmail.com 


\section{Introduction}

Vegetables and cereals are basic nutrition for the majority of animals including humans, now and in the recorded history. For better nutritional value the seeds of these plants have received some form of treatment, heating, fermentation or germination. Frequently, in the Western and industrialized world sprouting is limited only to the malting of cereals in the brewing practices, but in other parts of the world, sprouting is the main process of transforming feed grains in food.

Basil (Ocimum basilicum L.), belongs to the order Lamiales, family Lamiaceae and the genus Ocimum (http://www.theplantlist.org/tpl1.1/record/kew-136820 [1]), is an annual herbaceous plant which has it is origins in tropical and warm zones of the globe (R. HILTUNEN \& Y. HOLM [2]). Basil plant extract contains insecticidal and antimicrobial biological active constituents (O. MAKRI \& S. KINTZIOS [3]). Basil, also, showed a capability in UV protection investigated (M.C. COURREGES \& F. BENENCIA [4]). The study revealed that basil volatile oil exerted great sun protection factor (SPF) when used in addition in a sunscreen formula. A hydroalcoholic leaf extract reduced in mice skin tumor sizes with $20 \%$, by the presence of apigenin, an active compound in basil (T. DASGUPTA \& al [5]).

Because of it is brittleness and frailty, the basil plant (Ocimum basilicum L.), does not have a broad number of pesticides or insecticides. Some of it is defenses, manmade or natural, are predators that prey on pests, the unique basil fragrance that repels insects and phytopathogens, biological control agents like Bacillus thuringiensis against caterpillars, diatomaceous earth for snails. This aspect denote that alternative cultures are required instead of field crops to help proliferate the plant.

Charcoal provides an opportunity to increase soil fertility and the efficiency of nutrient absorption rate using renewable materials and locally available materials in a eco-friendly manner. Using charcoal does not affect our current resource pool, but makes a good and non-polluting use of already existing materials (J. LEHMANN \& S. JOSEPH [6]). LED or light-emitting diode is a new means for experiments on plant metabolites. M. AUBÉ $\&$ al [7] studies say that light from LEDs has a higher energy efficiency than any other light source. Using LEDs on buckwheat, especially red LED light, has proven effective in stimulating phenolic compounds (S.W. LEE \& al [8]) Red LED light treatments, based on G.D. GOINS $\&$ al [9] experiment, showed that the yield in biomass, in photosynthesis and growth rate of lettuce improved. H. LI $\&$ al [10] observed that blue LED light treatment improved chlorophyll rates in chinese cabbage. Green LED light can infiltrate deeper in the plants tissues which may increase photosynthesis (I. TERASHIMA \& al [11]).

In this context, the purpose of our work was to assess evaluate the influence of treatments with LED-s illumination (white, red, blue and green) and sunlight on the basil sprouts in terms of the rate of sprouts, the fresh weight (of sprouts, cotyledons, hypocotyls and roots) and the length (of hypocotyls and roots) of basil sprouts.

\section{Materials and Methods}

The vegetal biological material was constituted of basil (Ocimum basilicum L.), seeds that were obtained from a commercial source. Germination and sprouting occurred in a sterile environment. Seed sterilization eventuated as follows: seeds were immersed 30 seconds in a $2.5 \%$ sodium hypochlorite (L.B. DODE \& AL [12]; M.R. AZARAKHSH \& al [13]; E. A. GENADY \& al [14]) followed by three consecutive washes. Each wash was with a duration of 10 minutes, in sterile conditions and sterile distilled water (E. M. BADEA \& D. SĂNDULESCU [15]; D. CACHIȚĂ-COSMA \& al [16]). Seed inoculation was performed in transparent recipients on sterile gauze (I.M. ENACHE \& O. LIVADARIU [17]), wet with $20 \mathrm{ml}$ sterile distilled water and on sterilized grounded charcoal mixed with $20 \mathrm{ml}$ sterile distilled water. After inoculation the transparent recipients were kept under dark conditions for 72 hours.

The light-based treatments were fulfilled using five types of lights: sunlight and LED light with four spectra of light (cold white, deep red, high blue - O. LIVADARIU \& C. MAXIMILIAN [18] at Fagopyrum esculentum Moench. - and green - D. RAICIU \& al [19] at Allium sativum L. Sunlight or LED light regime was applied over a 16 hours photoperiod, for 11 days.

The seeds were incubated at a temperature of $23^{\circ} \mathrm{C} \pm$ $2^{\circ} \mathrm{C}$ photoperiod and a temperature of $20^{\circ} \mathrm{C} \pm 2{ }^{\circ} \mathrm{C}$ darkness period (I. M. ENACHE \& O. LIVADARIU [20]).

Technical characteristics of LED-s are: light flux $435 \mathrm{~lm}, 18 \mathrm{~W}$ power, $220 \mathrm{~V}$ voltage (O. LIVADARIU \& C. MAXIMILIAN [18]).

The experimental project was based on ten experimental variants, each with three repetitions:

- V1 - gauze substratum under white LED light,

- V2 - gauze substratum under red LED light,

- V3 - gauze substratum under blue LED light,

- V4 - gauze substratum under green LED light,

- V5 - gauze substratum under sunlight,

- V6 - charcoal substratum under white LED light,

- V7 - charcoal substratum under red LED light,

- V8 - charcoal substratum under blue LED light,

- V9 - charcoal substratum under green LED light and

- V10 - charcoal substratum under sunlight.

Statistical procedures. The experimental variants consisted of 30 basil (Ocimum basilicum L.) seeds per transparent recipients. Each experimental variants was done in triplicate. Data obtained from analysis was statistically examined. The rate of sprouts, the fresh weight of sprouts, cotyledons, hypocotyls and roots, and the length of hypocotyls and roots were determined. 


\section{Results and Discussion}

1. Determination of the rate of basil (Ocimum basilicum L.) sprouts by the influences, of substatum from gauze or charcoal, and the irradiation with white (V1 and V6), red (V2 and V7), blue (V3 and V8) and green (V4 and V9) LED-s or the irradiation with sunlight (V5 and V10).
The graph from Figure 1 shows that the highest values (30 sprouts per recipient) were obtained in the case were the experimental variants were treated with blue LED light and both gauze and charcoal were used as subtratum (V3/V8). The lowest sprouting rate (27 sprouts) was obtained in the case where red LED light treatment and gauze substratum (V2) was used. The other experimental variants had comparable results.

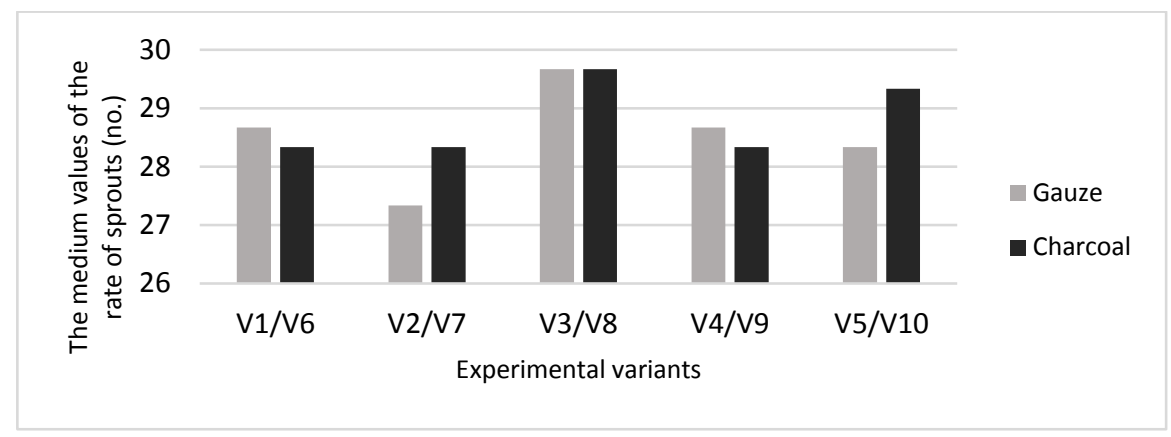

Figure 1. The medium values of the rate of Ocimum basilicum L. sprouts (no.), subject to the experimental variants (V1-V10).

2. Determination of the fresh weight of basil (Ocimum basilicum L.) sprouts by the influences, of substatum from gauze or charcoal, and the irradiation with white (V1 and V6), red (V2 and V7), blue (V3 and V8) and green (V4 and V9) LED-s or the irradiation with sunlight (V5 and V10).
Determination of the fresh weight of basil sprouts (Figure 2), indicated the fact that the highest value is in the case of the variant $\mathrm{V} 10(0.41 \mathrm{~g})$, and the lowest in V1 (0.23 g).

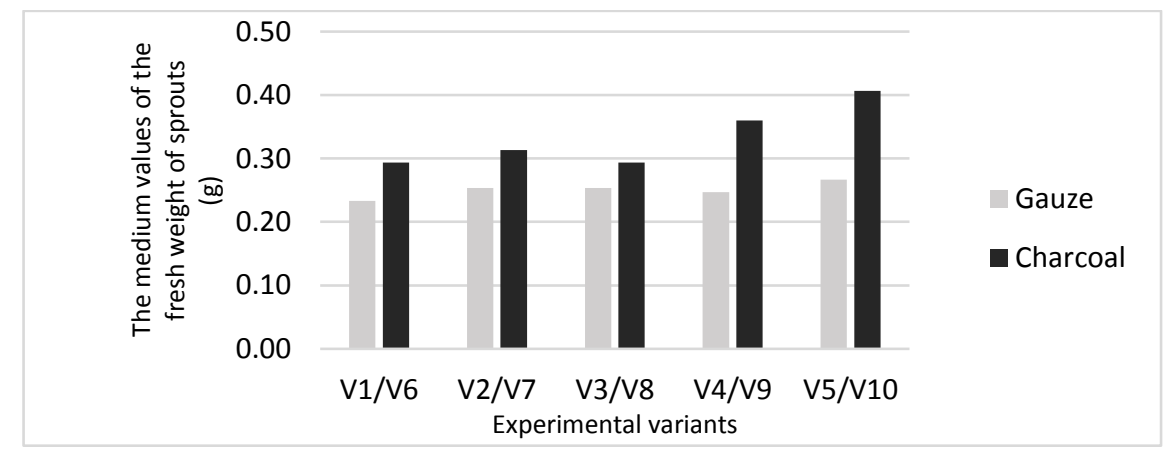

Figure 2. The medium values of the fresh weight of Ocimum basilicum L. sprouts (g), for experimental variants (V1-V10).

Comparable values were obtained in the case of V1/V6 (0.23 g/0.29 g), V2/V7 (0.25 g/0.31 g), V3/V8 $(0.25 \mathrm{~g} / 0.29 \mathrm{~g})$, white, red, blue LED light, with a visible difference in the variants where charcoal was used as substratum. An increase in weight was achieved in the case of V9 (green LED) and V10 (sunlight), respectively $0.36 \mathrm{~g}$ and $0.41 \mathrm{~g}$, meanwhile in the case where gauze was used, there were no signifiant or no differences at all in weight.
The determination of the fresh weight of cotyledons of basil sprouts (Figure 3), pointed out that the highest value was achieved in the case of the variant with charcoal substratum and green LED light (V9 with $0.17 \mathrm{~g}$ ) and the lowest when gauze subtratum and sunlight was used (V5 with $0.08 \mathrm{~g}$ ). The remaining values are do not vary much with the only difference that the values are higher when charcoal substratum was used in comparison to gauze subtratum. 


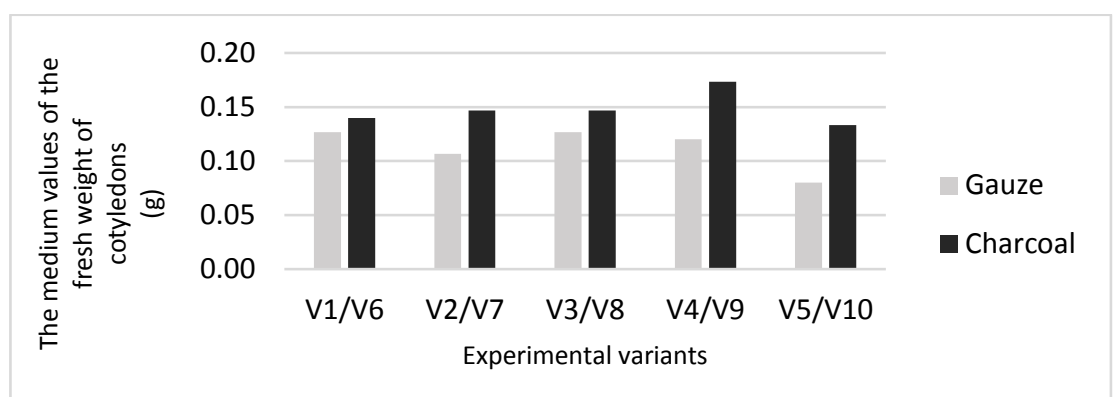

Figure 3. The medium values of the fresh weight of Ocimum basilicum L. cotyledons (g), for experimental variants (V1-V10).

Determination of the fresh weight of hypocotyls of basil sprouts (Figure 4), showed that highest values were obtained when sunlight was used, V5/V10 (0.16 g/0.21 g), and lowest in white LED light with gauze substratum, V1 $(0.05 \mathrm{~g})$, and in blue LED light with charcoal substratum, V8 $(0.11 \mathrm{~g})$. The same approximate results were obtained when using white, red, blue and green LED with the only difference that in with the charcoal substratum higher values were attained.

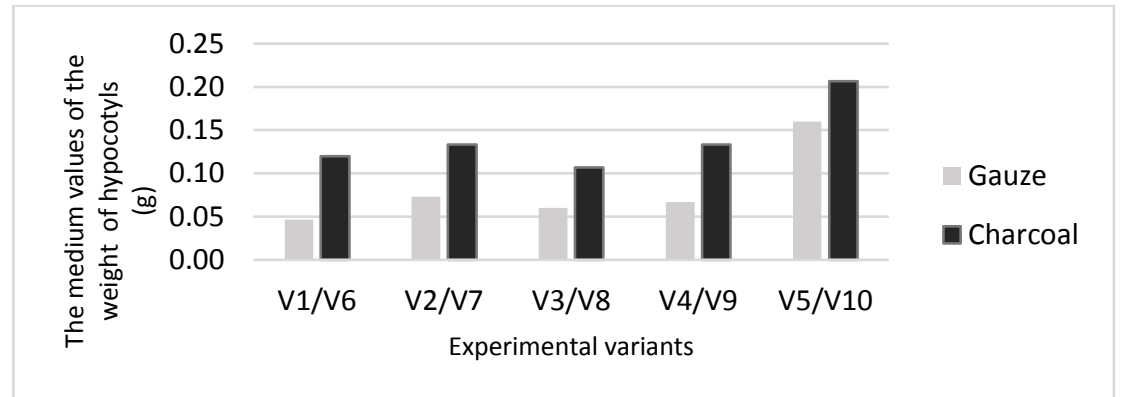

Figure 4. The medium values of the fresh weight of Ocimum basilicum L. hypocotyls (g), for experimental variants (V1-V10).

The graph from Figure 5 demonstrates that the value of fresh weight of roots peaked when gauze subtratum and red LED light was used (V2 with $0.07 \mathrm{~g}$ ) followed closely by V10 and V3 variants and had the lowest value when gauze and sunlight was used (V5 with $0.03 \mathrm{~g}$ ) followed by V6 and V7.

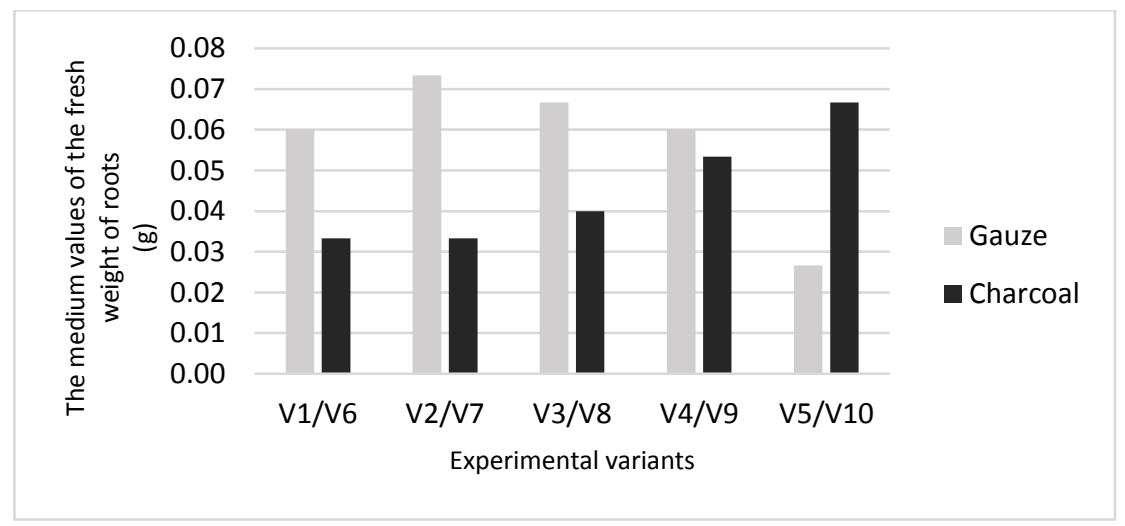

Figure 5. The medium values of the fresh weight of Ocimum basilicum L. roots (g), for experimental variants (V1-V10). 
3. Determination of the length of basil (Ocimum basilicum L.) sprouts (hypocotyls and roots) by the influences, of substatum from gauze or charcoal, and the irradiation with white (V1 and V6), red (V2 and V7), blue (V3 and V8) and green (V4 and V9) LED-s or the irradiation with sunlight (V5 and V10).

Determination of hypocotyl length (Figure 6), exhibited that using charcoal as subtratum higher lengths are achieved in comparison to gauze substratum. The highest value was obtained in the charcoal subtratum variants under sunlight (V10) $2.41 \mathrm{~cm}$ followed by white LED light $(2.30 \mathrm{~cm})$ and red LED light $(2.25 \mathrm{~cm})$. When gauze subtratum was used the highest length obtained was when using sunlight (V5 with $1.73 \mathrm{~cm}$ ), while the rest of the variants had almost the same hypocotyl lenght.

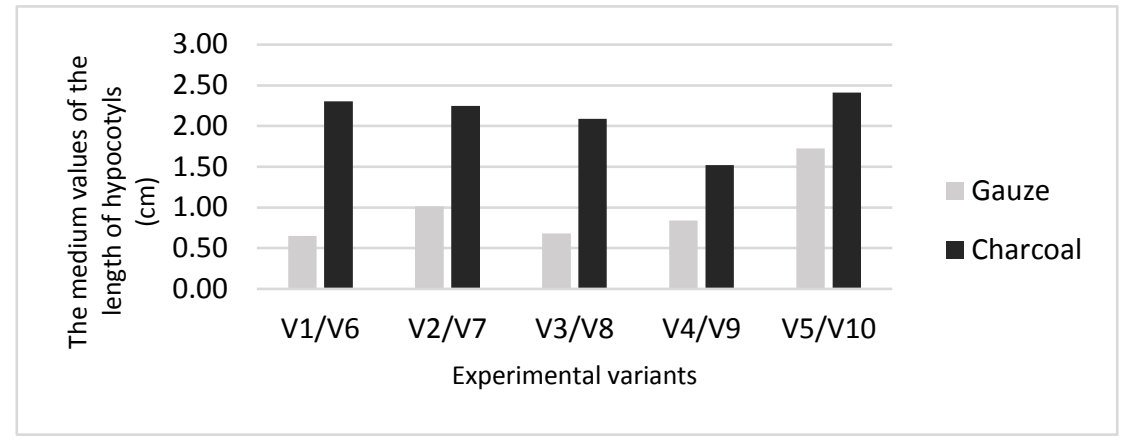

Figure 6. The medium values of the length of Ocimum basilicum L. hypocotyls $(\mathrm{cm})$, for experimental variants (V1-V10).

Root length (Figure 7), in the case of the gauze substratum achieved substantial differences in comparison with charcoal substratum. When white LED light was used, in the case of the charcoal substratum (V6) the lowest root length value was obtained $(0.40 \mathrm{~cm})$, opposed to the case of the gauze substratum (V1) where the highest root length value was obtained $(1.95 \mathrm{~cm})$. The experimental variants where gauze was used (V1, V2, V3, V4 and V5) achieved about the same size, between $1.65 \mathrm{~cm}$ and $1.95 \mathrm{~cm}$, whilst the charcoal subtratum sprouts under red, blue and green LED light (V7, V8, V9) the same size was obtained $(1.19 \mathrm{~cm}, 1.16 \mathrm{~cm}, 1.30 \mathrm{~cm})$.

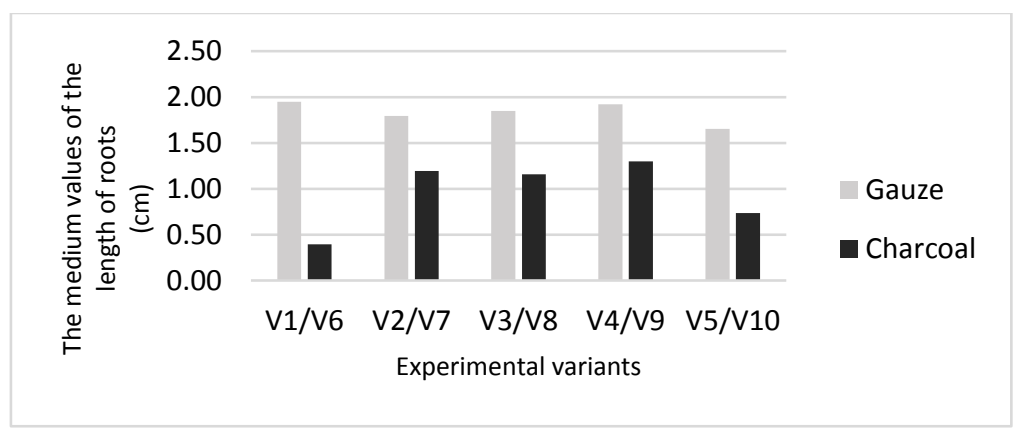

Figure 7. The medium values of the length of Ocimum basilicum L. roots $(\mathrm{cm})$, for experimental variants (V1-V10).

The results above demonstrate that the source of light (sunlight or LEDs), color of the LEDs light and the substrate that was used play a role that influences phytomorphology.

Regarding sprouting rate, the color or the nature of the light source played a little or no part, influencess. Whilst the substratum type showed that using charcoal delays the sprouting process.

Concerning the fresh weight of basil sprouts, sunlight induced the highest weight value in comparison to the other types of light. Charcoal substratum proved more effective in stimulating basil sprouts weight than gauze substratum.
In terms of the fresh weight of cotyledons, while using charcoal as substratum, the blue LED light treatment has facilitated the growth of cotyledons the most. The fresh weight of cotyledons is increased by using charcoal instead of gauze.

Looking at the average values of the root length, the conclusion is that white LED light and sunlight conjunctively with charcoal substratum determined a deficient root growth in length.

While the length of the variant with the deficient root growth was small, it's weight was comparable with the gauze variants which registered high yield in root length and weight. 
The hypocotyl length and fresh weight determinations have showed that using LEDs and charcoal substratum may improve the length of the hypocotyls of basil sprouts, to the detriment of their weight. Using sunlight treatment in both substratum variants stimulated the hypocotyl development regarding length and weight.

\section{Conclusion}

The light source, color of the light source and the substratum played a role in the sprouts development.

The fresh weight of the sprouts was well stimulated by the charcoal substratum and by the sunlight.

Regarding the fresh weight of the cotyledons the blue LED light and charcoal facilitated the growth the most.

Charcoal substratum conjunctively used with white LED light determined a deficient growth concerning root length, but in terms of weight this treatment stimulated weight the most.

Concerning hypocotyl length and weight, LED-s and charcoal improved length but to the detriment of their weight. No matter the substratum, sunlight stimulated hypocotyl development.

\section{References}

1. http://www.theplantlist.org/tpl1.1/record/kew-136820

2. HILTUNEN R, HOLM Y. Basil: the genus Ocimum. Publisher Harwood Academic Publishers, Amsterdam, Netherlands, 1999, pp. 182.

3. MAKRI O, KINTZIOS S. Ocimum sp. (Basil): Botany, Cultivation, Pharmaceutical Properties, and Biotechnology. Journal of Herbs Spices \& Medicinal Plants, 13(3):123-150 (2008). DOI: 10.1300/J044v13n03_10\}

4. COURREGES MC, BENENCIA F. In vitro antiphagocytic effect of basil oil on mouse macrophages. Fitoterapia, 73(5): 369-374 (2002).

5. DASGUPTA T, RAO AR, YADAVA PK. Chemomodulatory efficacy of Basil leaf (Ocimum basilicum) on drug metabolizing and antioxidant enzymes, and on carcinogen-induced skin and forestomach papillomagenesis. Phytomedicine, 11(2-3): 139-151 (2004).

6. LEHMANN J, JOSEPH S. Biochar for Environmental Management: An Introduction. Biochar for Environmental Management - Science and Technology, 1: 1-12, pp. 6 (2009).

7. AUBÉ M, ROBY J, KOCIFAJ M. Evaluating Potential Spectral Impacts of Various Artificial Lights on Melatonin Suppression, Photosynthesis, and Star Visibility. PLOS ONE, 8(7): e67798 (2013). https://doi.org/10.1371/journal.pone.0067798

8. LEE S-W, SEO JM, LEE M-K, CHUN J-H, ANTONISAMY P, ARASU MV, SUZUKI T., AL-DHABI NA, KIM S-J. Influence of different LED lamps on the production of phenolic compounds in common and Tartary buckwheat sprouts. Industrial Crops and Products, 54:320-326 (2014). https://doi.org/10.1016/j.indcrop.2014.01.024
9. GOINS GD, RUFFE LM, CRANSTON NA, YORIO NC, WHEELER RM, SAGER J.C. Salad crop production under different wavelengths of red lightemitting diodes (LEDs). SAE Technical Paper, 31 st International Conference on Environmental Systems, July 9-12, Orlando, Florida, USA, pp. 1-9 (2001).

10. LI H, TANG C, XU Z, LIU X, HAN X. Effects of Different Light Sources on the Growth of Non-heading Chinese Cabbage (Brassica campestris L.). Journal of Agricultural Science, 4(4):262-273 (2012). DOI: 10.5539/jas.v4n4p262

11. TERASHIMA I, TAKASHI F, TAKESHI I, WAH SC, RIICHI O. Green Light Drives Leaf Photosynthesis More Efficiently than Red Light in Strong White Light: Revisiting the Enigmatic Question of Why Leaves are Green. Plant and Cell Physiology, 50(4): 684-697 (2009). https://doi.org/10.1093/pcp/pcp034

12. DODE LB, BOBROWSKI VL, BRAGA EJB, SEIXAS FK, SCHUCH MW. In vitro propagation of Ocimum basilicum L. (Lamiaceae), Acta Sci. Biol. Sci., 25(2):435-437 (2003).

13. AZARAKHSH MR, ASRAR Z, MANSOURI H. Effects of seed and vegetative stage cysteine treatments on oxidative stress response molecules and enzymes in Ocimum basilicum L. under cobalt stress. Journal of Soil Science and Plant Nutrition, 15(3):651-662 (2015). https://scielo.conicyt.cl/pdf/jsspn/v15n3/aop4415.pdf

14. GENADY EA, AHMED SS, FAHMY AH, ASHOUR RM. Copper sulphate nanoparticles enhance growth parameters, flavonoid content and antimicrobial activity of Ocimum basilicum Linnaeus. Journal of American Science, 13(4):108-114 (2017), ISSN 1545-1003 (print), ISSN 2375-7264 (online). http://www.jofamericanscience.org. doi:10.7537/marsjas130417.14 (http://www.jofamericanscience.org/journals/amsci/am130417/14_32036jas130417_108_114.pdf).

15. BADEA EM, SĂNDULESCU D. Bio Tehnologii Vegetale. Editura Fundația Biotech, București, 2001, pp. 21.

16. CACHIT,Ă-COSMA D, DELIU C, RAKOSY-TICAN L, ARDELEAN A. Tratat de biotehnologie vegetală, Editura Dacia, Cluj-Napoca, vol. I, 2004, pp. 105.

17. ENACHE IM, LIVADARIU O. Preliminary results regarding the testing of treatments with lightemitting diode (LED) on the seed germination of Artemisia dracunculus L. Scientific Bulletin. Series F. Biotechnologies, ISSN 2285-1364, vol. XX, pp. 52, 53 (2016).

18. LIVADARIU O, MAXIMILIAN C. Studies Regarding Treatments of LED-s Emitted Light on Sprouting Fagopyrum esculentum Moench., Bulletin UASVM Animal Science and Biotechnologies, 74(2): 102-111 (2017).

19. RAICIU D, LIVADARIU O, MAXIMILIAN C, CRET UM AM. The assesment of the effect induced by LED-s irradiation on garlic sprouts (Allium sativum L.). Romanian Biotechnological Letters, 23(6): 14187-14192 (2018). 